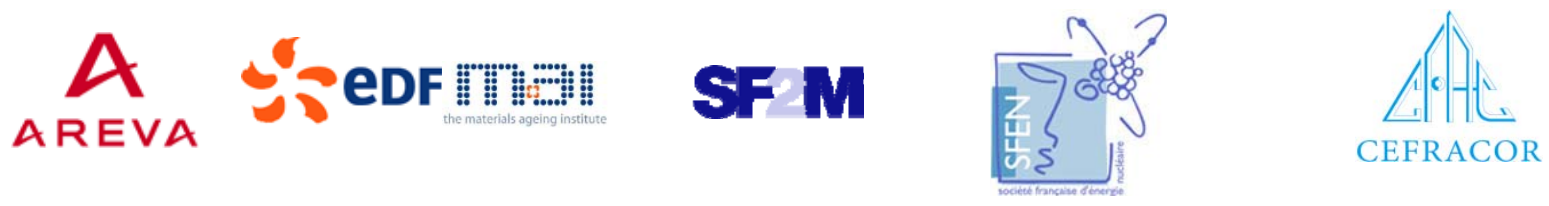

\section{MIN口S}

Centre of Excellence for Nuclear Materials

\section{Workshop}

Materials Innovation for Nuclear Optimized Systems
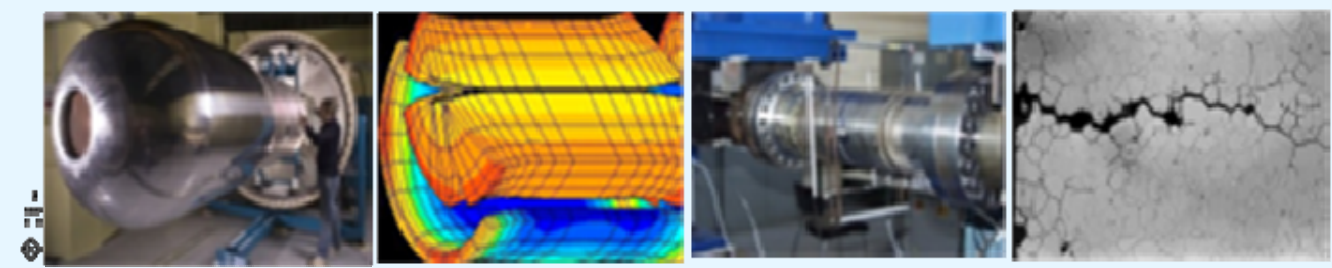

December 5-7, 2012, CEA - INSTN Saclay, France

Laurent CHAFFRON et al.

CEA (France)

Innovative SiC/SiC Composite for Nuclear

Applications

Workshop organized by:

Christophe GALLÉ, CEA/MINOS, Saclay - christophe.galle@cea.fr Constantin MEIS, CEA/INSTN, Saclay - constantin.meis@cea.fr 


\title{
Innovative SiC/SiC Composite for Nuclear Applications
}

\author{
Laurent CHAFFRON ${ }^{1}$, Cédric SAUDER ${ }^{1}$, Christophe LORRETTE ${ }^{1}$, Laurent BRIOTTET ${ }^{2}$, \\ Aurore MICHAUX ${ }^{1}$, Lionel GÉLÉBART ${ }^{1}$, Aurélie COUPÉ ${ }^{1}$, Maxime $Z$ ZABIEGO $^{3}$, \\ Marion LE FLEM ${ }^{1}$, Jean-Louis SÉRAN ${ }^{1}$ \\ ${ }^{1}$ CEA-DEN-DMN, Service de Recherche Métallurgiques Appliquées, SRMA (Saclay, France) \\ ${ }^{2}$ CEA-DRT, Laboratoires d'Innovation pour les Technologies des Energies, LITEN (Grenoble, France) \\ ${ }^{3}$ CEA-DEN-DEC, Service d'Etudes et de Simulation du Comportement des Combustibles, SESC (Cadarache, France)
}

Among various refractory materials, $\mathrm{SiC} / \mathrm{SiC}$ ceramic matrix composites (CMC) are of prime interest for fusion and advanced fission energy applications, due to their excellent irradiation tolerance and safety features (low activation, low tritium permeability,...). Initially developed as fuel cladding materials for the Fourth generation Gas cooled Fast Reactor (GFR), this material has been recently envisaged by CEA for different core structures of Sodium Fast Reactor (SFR) which combines fast neutrons and high temperature $\left(500^{\circ} \mathrm{C}\right)$. Regarding fuel cladding generic application, in the case of GFR, the first challenge facing this project is to demonstrate the feasibility of a fuel operating under very harsh conditions that are (i) temperatures of structures up to $700^{\circ} \mathrm{C}$ in nominal and over $1600^{\circ} \mathrm{C}$ in accidental conditions, (ii) irradiation damage higher than $60 \mathrm{dpa}_{\mathrm{sic}}$, (iii) neutronic transparency, which disqualifies conventional refractory metals as structural core materials, (iv) mechanical behavior that guarantees in most circumstances the integrity of the first barrier (e.g.: $\varepsilon>0.5 \%$ ), which excludes monolithic ceramics and therefore encourages the development of new types of fibrous composites SiC/SiC adapted to the fast reactor conditions. No existing material being capable to match all these requirements, CEA has launched an ambitious program of development of an advanced material satisfying the specifications [1]. This project, that implies many laboratories, inside and outside CEA, has permitted to obtain a very high quality compound that meets most of the challenging requirements. We present hereinafter few recent results obtained regarding the development of the composite. One of the most relevant challenges was to make a gastight composite up to the ultimate rupture. Indeed, multicraking of the matrix is the counterpart of the damageable behavior observed in these amazing compounds. Among different solutions envisaged, an innovative one has been successful. It consists of inserting a metallic layer between two tubes of CMC [2]. The concept, illustrated in figure 1, guaranties a perfect helium tightness up to fracture of the CMC.

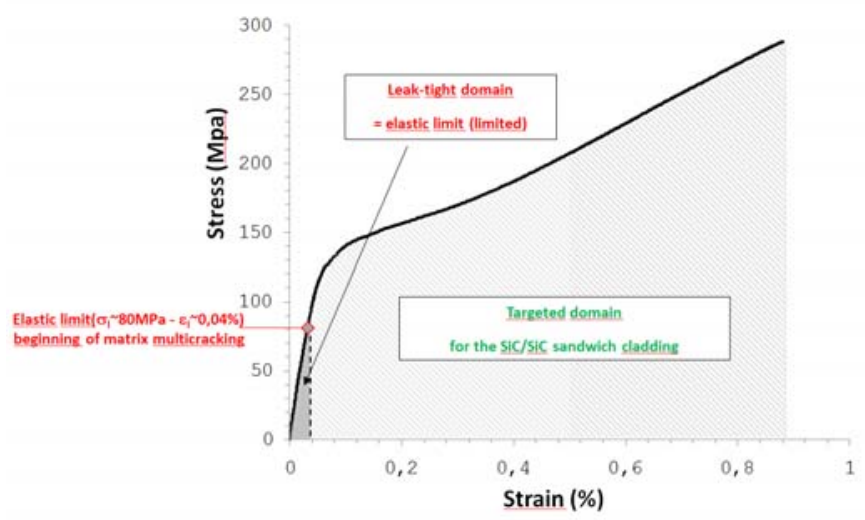

Fig. 1: Sandwich cladding concept: tightness is ensured up to CMC failure thanks to the elastic metallic layer.

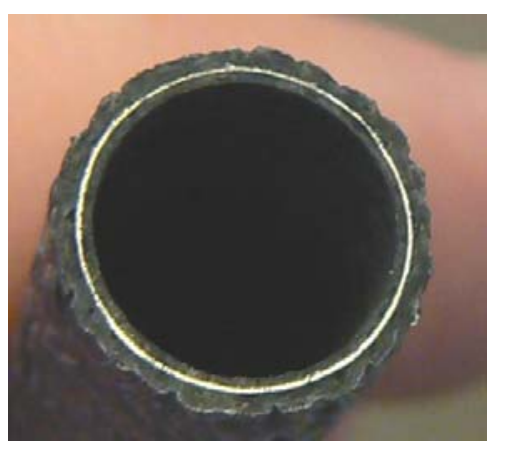

Fig. 2: Sandwich cladding Cross section (metal is in white). 
Another challenge was to prepare a representative cladding with very strict geometrical tolerances. Revisiting the fabrication of the entire breading process has allowed to ensure a perfect geometry of the final tube. Thanks to the high quality of manufacture and the high level of purity of composite materials manufactured at CEA, few tens of CMC objects (tubes, disks and plates) have been prepared in order to be irradiated in the Russian reactor "BOR 60". For the first time, composite materials will be submitted to swift neutrons at very high damaging doses (up to $80 \mathrm{dpa}$ sic) between 400 and $520^{\circ} \mathrm{C}$. Post irradiation examinations expected for 2015 should give reliable results on the behavior of this multi-materials component. In parallel, other basic researches are conducted to improve the properties of the CMC and round off the understanding [3, 4, 5]. Some new results allowed to extend the field of use of the CMC through an optimization of the interphase of the composite. The figure 4 shows the relative elongation of a CMC after a two hours dwell time annealing in argon at different temperatures: optimized composite can sustain very high temperature without drastic drop of its mechanical properties.

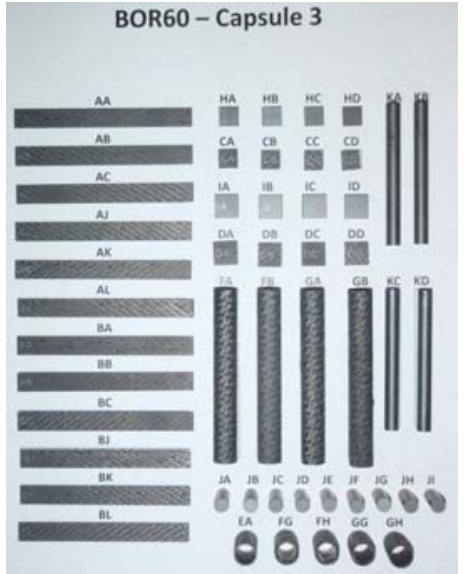

Fig. 3: CMC specimen prepared for BOR60 irradiation

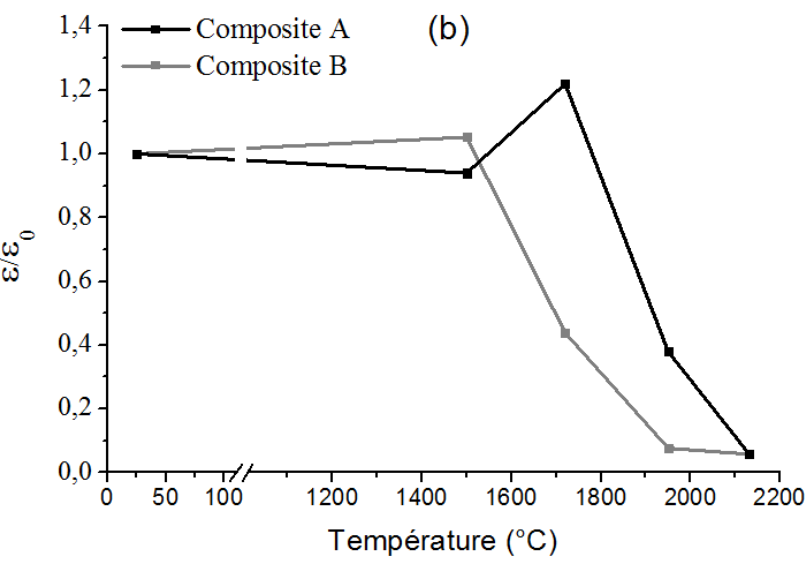

Fig. 4: Evolution of the relative elongation of two composites with the annealing temperature: optimized CVI conditions to improve mechanical properties.

\section{References}

[1] L. Chaffron, J. L. Séran, C. Sauder, C. Lorrette, A. Michaux, L. Gélébar1, A. Coupé, SiC/SiC Composite Materials for Fast Reactor Applications. Proceedings of ICAPP 2011, Nice, France, May 2-5, 2011, Paper 11433.

[2] M. Zabiégo, C. Sauder, C. Lorrette, P. Guédeney, Tube multicouche amélioré en matériau composite à matrice céramique, gaine de combustible nucléaire en résultant et procédés de fabrication associés.Patent submitted 1 August 2011, in French.

[3] C. Sauder, J. Lamon, Influence of fiber surface roughness on mechanical behaviour of SiC/SiC minicomposites with Hi-Nicalon S and SA3 reinforcement. $35^{\text {ème }}$ International Congress on Advanced Ceramic and Composites, Daytona beach 25 Janvier 2011.

[4] E. Buet, C. Sauder, S. Poissonnet, P. Brender, R. Gadiou, C. Vix-Guterl, Influence of chemical and physical properties of the last generation of silicon carbide fibres on the mechanical behaviour of SiC/SiC composite. Journal of the European Ceramic Society, 2012. 32(3): p. 547-557.

[5] A. Coupé, H. Maskrot, E. Buet, A. Renault, P.J. Fontaine, L. Chaffron, Dispersion Behavior of Laser-synthesized silicon carbide nanopowders in ethanol for Electrophoretic Infiltration. Journal of the European Ceramic Society, Vol 32, Issue 14, 3837-3850, 2012. 
C. Sauder, C. Lorrette, A. Michaux, L. Gélébart, E. Buet, S Poissonnet, A Coupé, J. Braun, L Briottet, M. Zabiego, J.L. Séran, M. Le Flem, L. Chaffron 


\section{CEA CONTEXT}

\section{MINDS}

Developpment of refractory materials for pin cladding of 4th generation reactors

- R\&D mostly driven by GFR fuel objectives (2004-2010)

- Recently extended to other applications : SFR \& PWR

\section{Focus on SiC/SiC composites:}

$\checkmark$ Refractory material $\left(>>1000^{\circ} \mathrm{C}\right)$

$\checkmark$ Irradiation resistance

$\checkmark$ Low activation

$\checkmark$ Neutron transparency

$\checkmark$ Corrosion resistance

Issues: gastightness + mechanical properties + thermal properties 


\section{CEA WHAT IS A SIC/SIC COMPOSITE?}

$\because$ MINDS

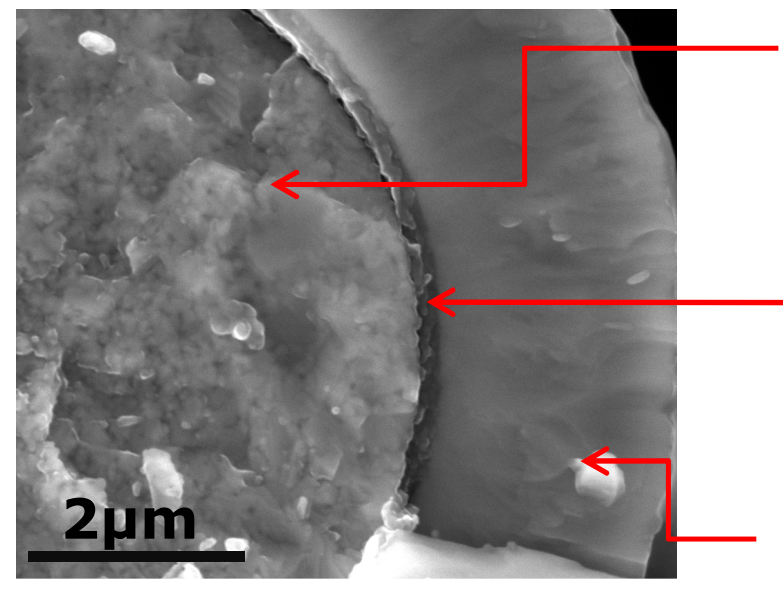

Fibre: ensures the mechanical strenght

Interphase: bonding between fiber and matrix

Matrix: protects the fiber and displys load transfer
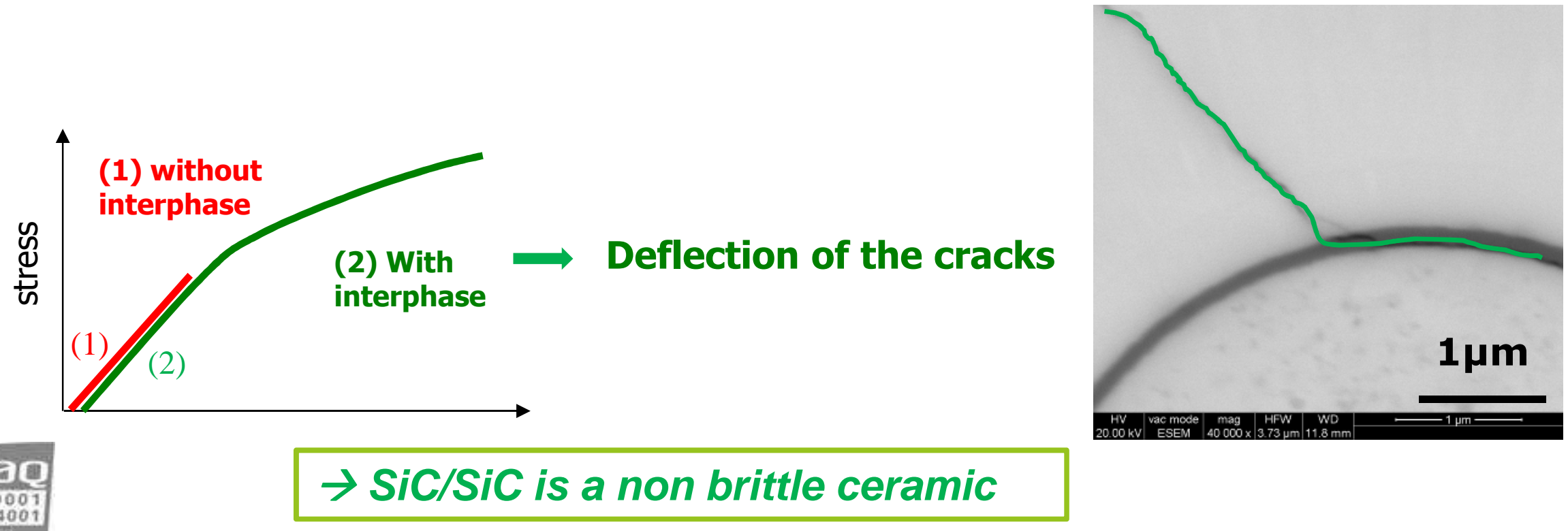


\section{Cea WHICH SIC/SIC FOR NUCLEAR APPLICATION?}

¿MINDS Choice of the fiber:

Stability under irradiation $\Rightarrow$

Hi-Nicalon S ou Tyranno SA3 fibers only

Stability at high temperature $\Rightarrow$

Tyranno SA3 fibers looks better

Thermal conductivity $\Rightarrow$

Tyranno SA3 fibers looks better

Cost $\Rightarrow$

Tyranno SA3 fiber is cheaper (30\%)

\begin{tabular}{|l|r|r|}
\hline & HNS & TSA3 \\
\hline Thermal stability & $\odot$ & $\odot$ \\
\hline Thermal conductivity & $\odot$ & $\odot$ \\
\hline Cost & $\odot$ & $\odot$ \\
\hline Mechanical properties & $\odot$ & $\odot$ \\
\hline
\end{tabular}

Choice of the interphase: PyC

Choice of the matrix: SiC CVI

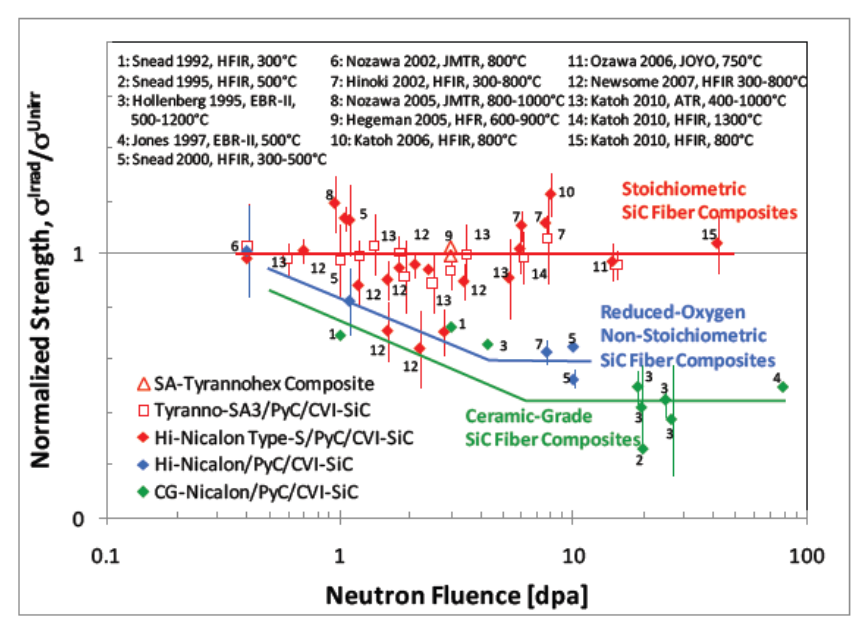

TSA is the target!
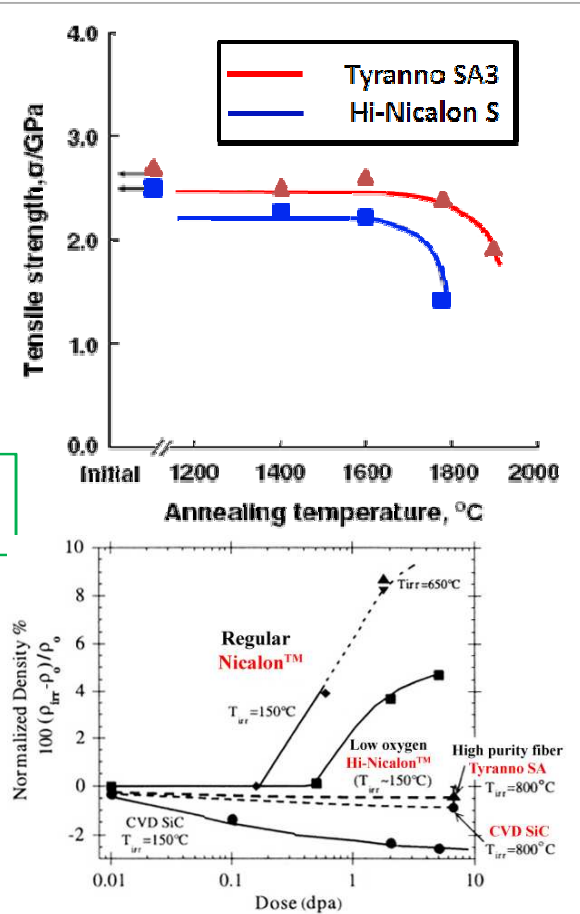


\section{THE MAIN CONCERNS FOR PIN CLADDING}

\section{MINDS}
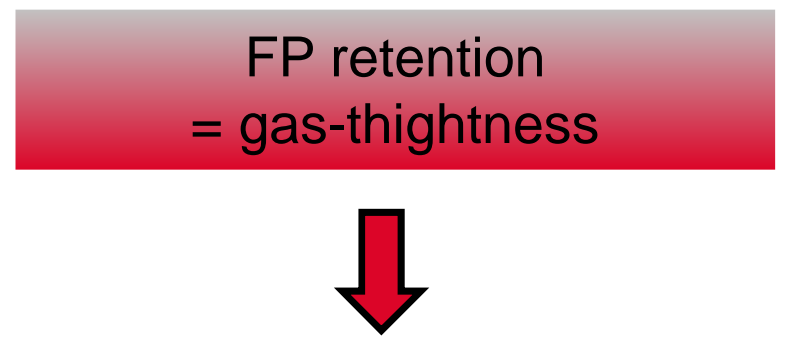

$\mathrm{SiC} / \mathrm{SiC}$ is not gastight upon its linear elastic domain.

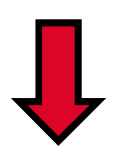

Introduction of a liner for gas-tightness $=$ CEA sandwich concept
Thermal exchange $=$ High $\lambda$

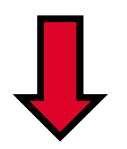

$\lambda_{\mathrm{Sic}}$ is lowered under irradiation (highly lowered at low temperatures)

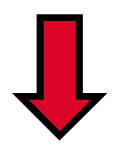

- Deal with it !

- Use of SA3 reinforcement

- Process a specific matrix for composites $\Rightarrow$ very long term work
Irradiation mechanical behavior

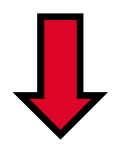

\section{Strain to failure} $\varepsilon_{R}>0,5 \%$

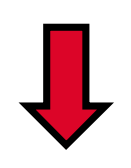

Ok with HNS

No solutions with SA3 Look for high dose irradiated mechanical behavior.

Goal: $\rightarrow$ Development of a gastight component prepared from HNS SiC/SiC composite 


\section{Cea PROCESSING : INFLUENCE OF BRAIDING AND GRINDING}

\section{MINDS}
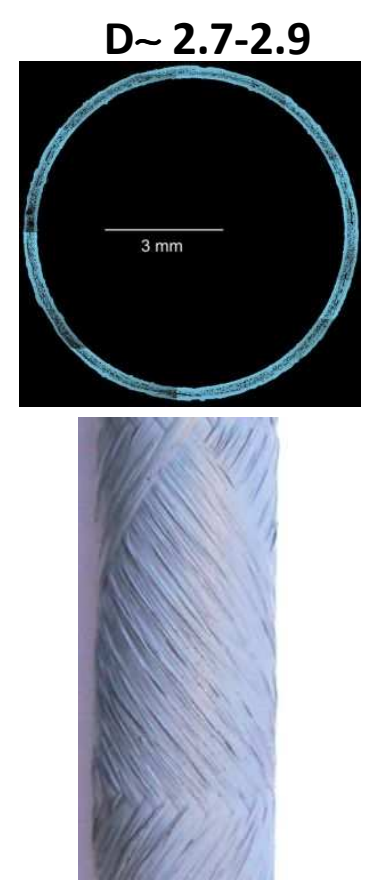

Filament Winding
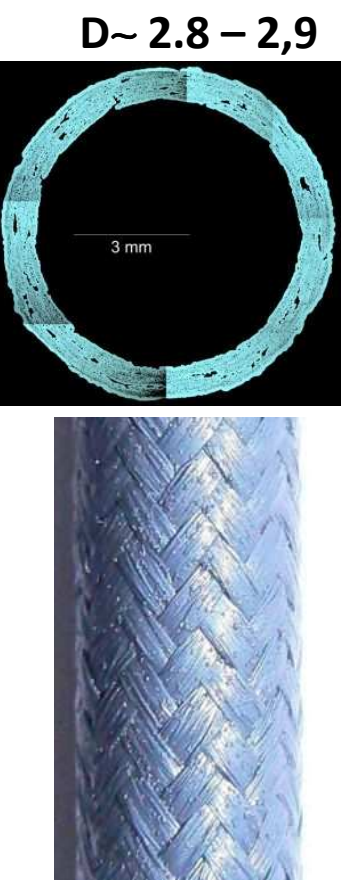

2D braiding
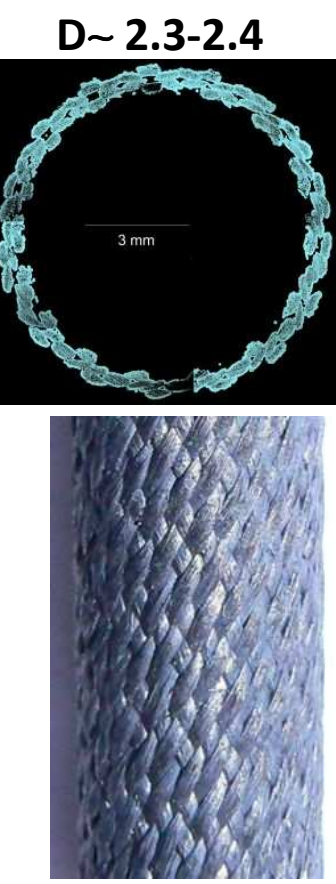

3D braiding

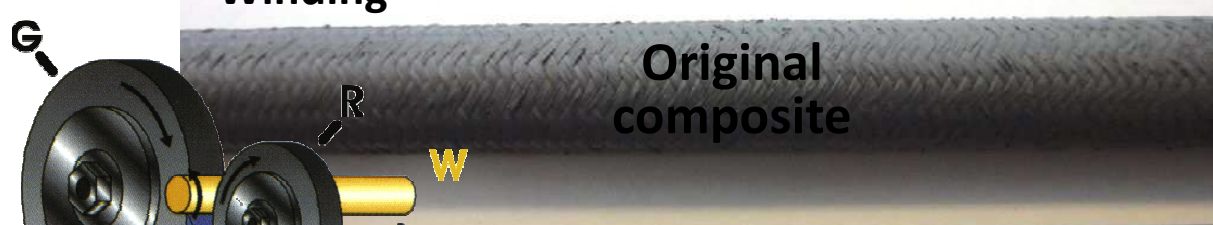

\section{Grinded (machined)}

- Properties can be tailored thanks to appropriate braiding

- Grinding has no significant effect on CMC 


\section{CQD CHARACTERIZATION: WHICH TEMPERATURE LIMITATION?}

\section{MINDS}

Influence of a thermal treatment ( $2 \mathrm{~h}$ in $\mathrm{Ar}$ ) on mechanical properties
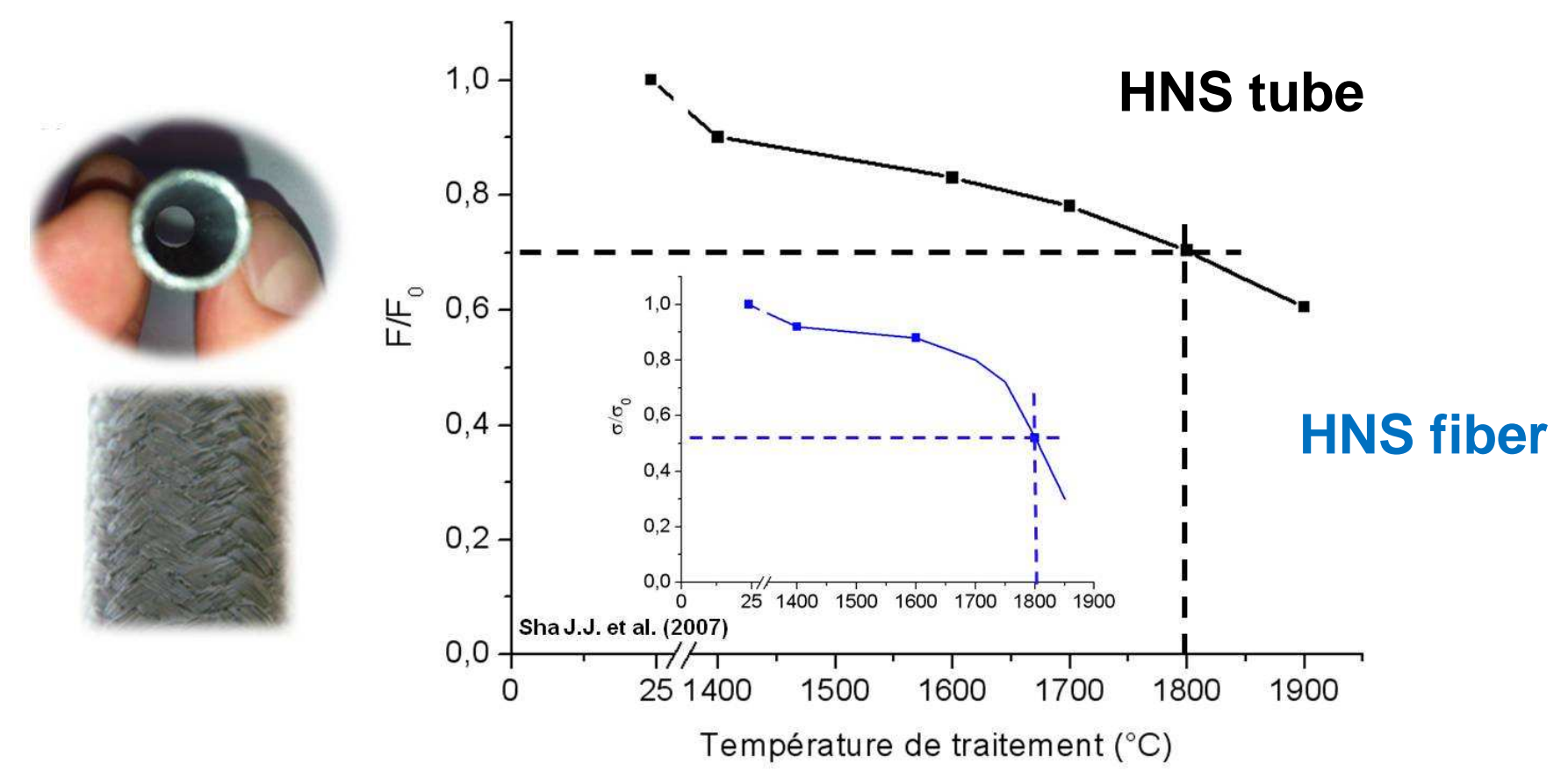

\section{$\mathrm{CVI} \mathrm{SiC/SiC} \mathrm{tube} \mathrm{is} \mathrm{not} \mathrm{sensitive} \mathrm{to} \mathrm{very} \mathrm{high} \mathrm{temperature}$} in inert atmosphere 


\section{Cea CHARACTERIZATION : FATIGUE}

\section{MINDS}

\section{Reference SiC/SiC material for Pin cladding:}

FW (459) 1 layer + 2D braiding (459) 2 layers
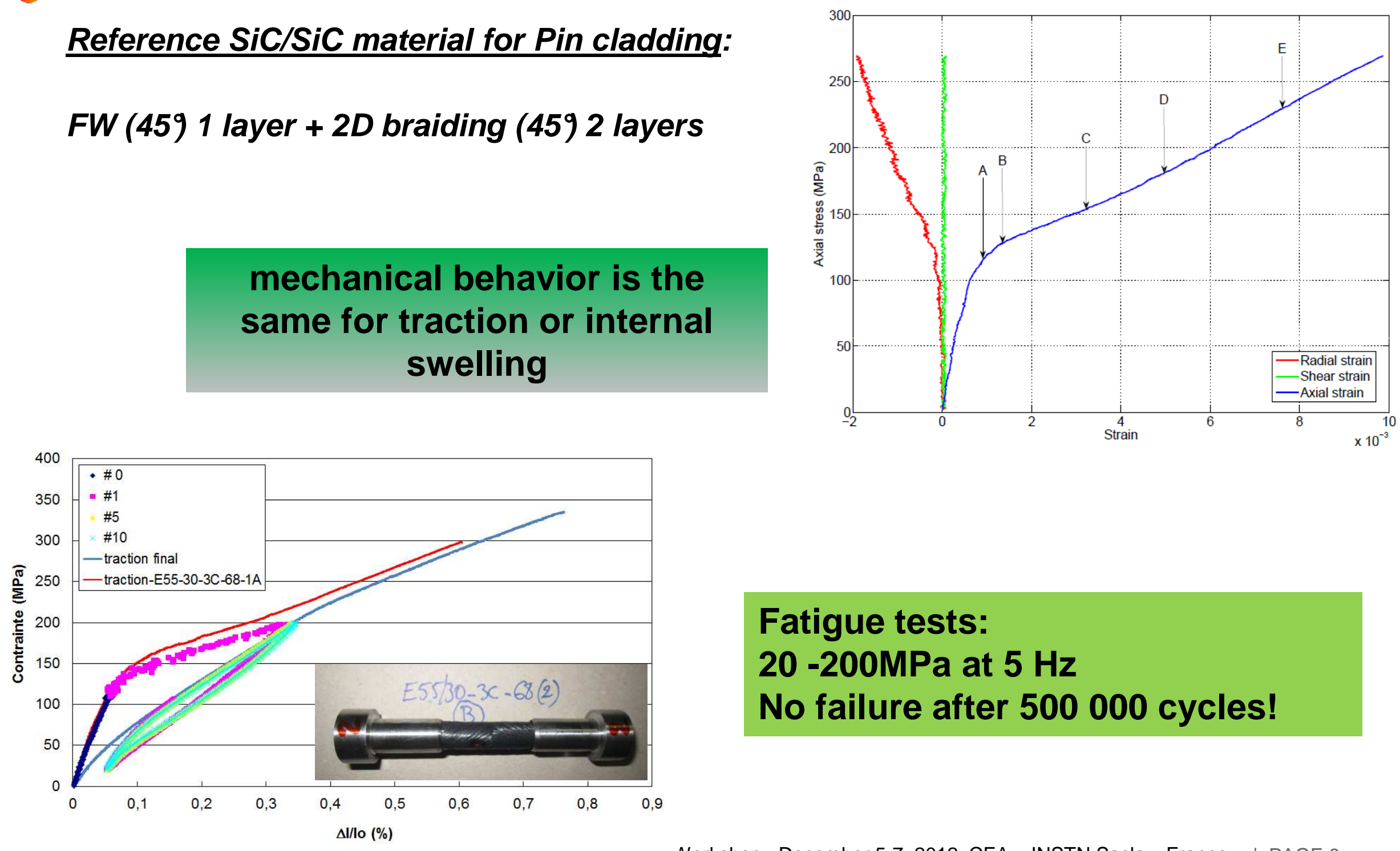

Fatigue tests:

$20-200 \mathrm{MPa}$ at $5 \mathrm{~Hz}$

No failure after 500000 cycles! 


\section{CHARACTERIZATION : DIMENSIONNING}

\section{MINDS}

\section{Patents:}

$\Rightarrow$ Control of dimensions and tolerances of CMC composites

\section{CEA/LTMEX Products}

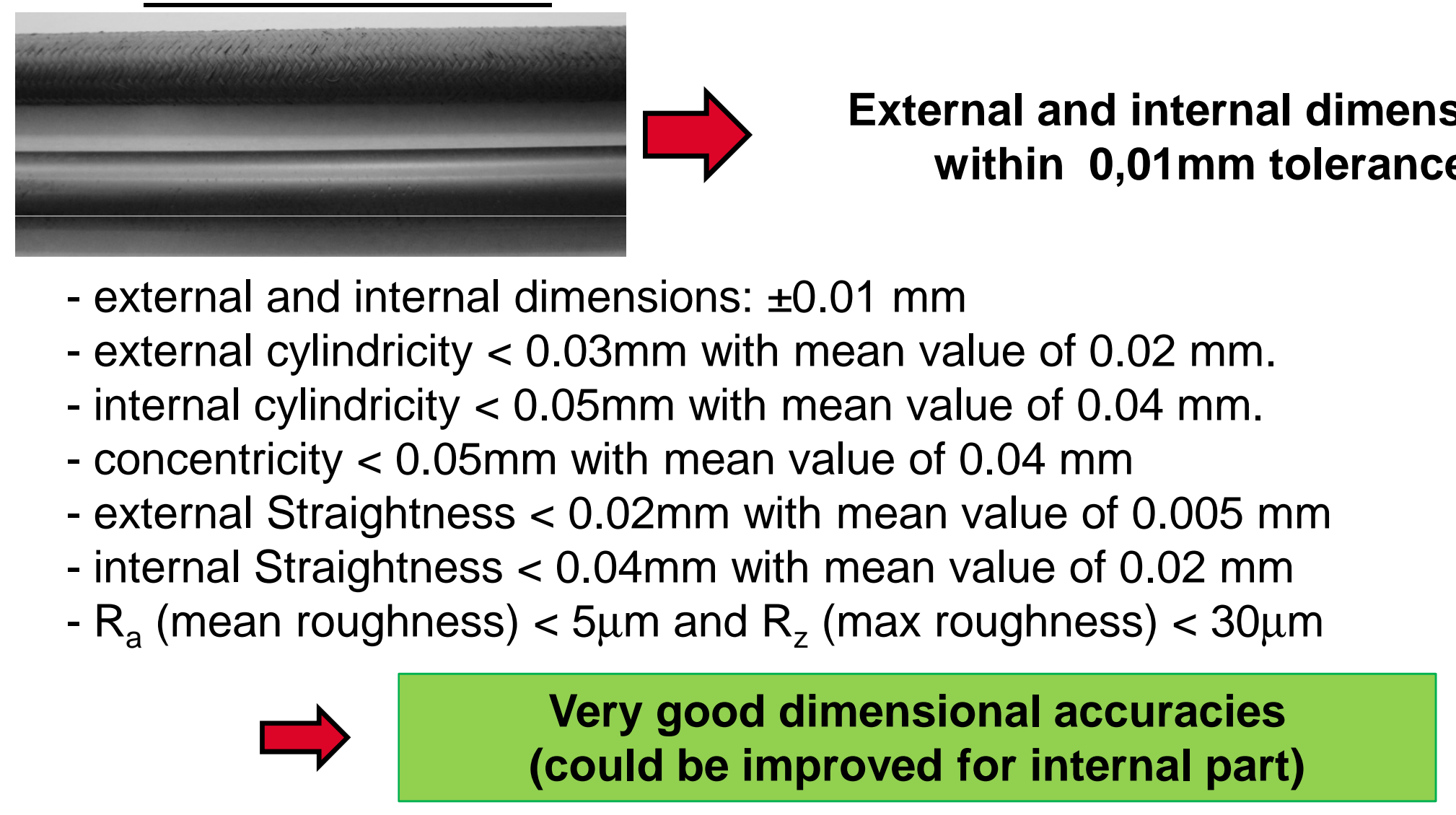




\section{CQZ CHARACTERIZATION: IMPURITIES CONCENTRATION}

\section{MINDS}
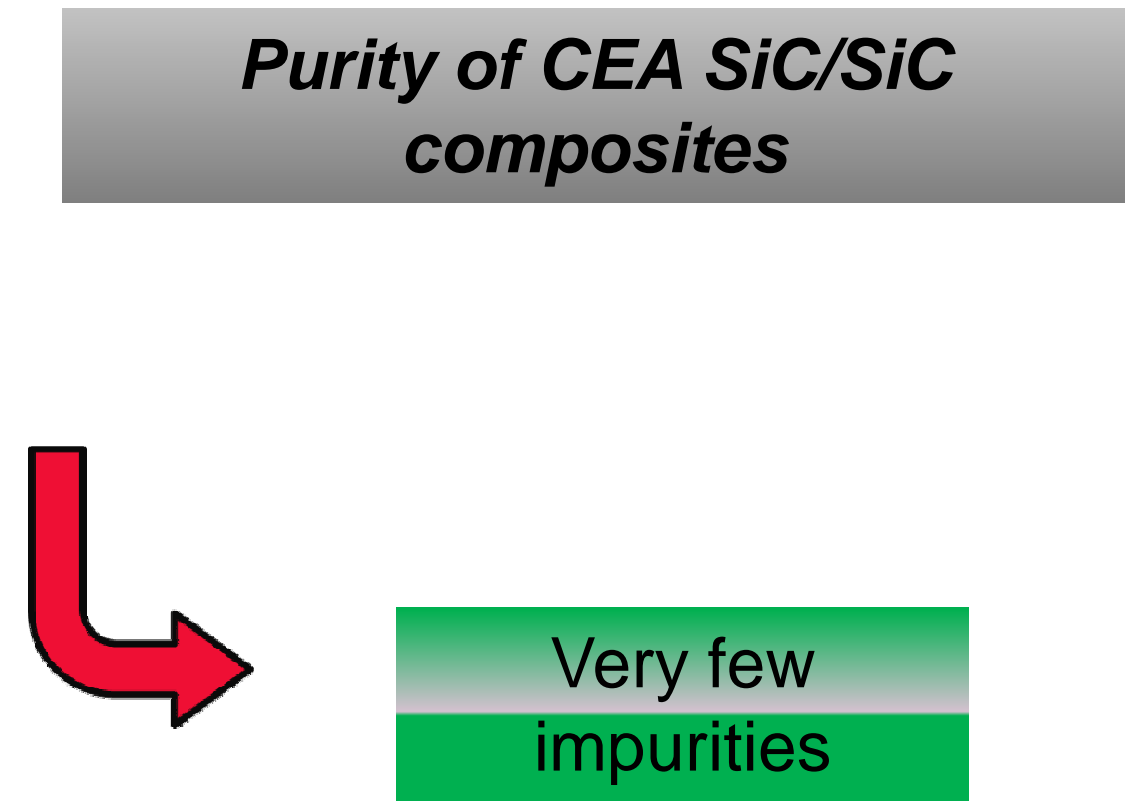

Residual Impurities (Fe, S, N, O, H) belong to $\mathrm{Hi}$-Nicalon $\mathrm{S}$ fibers 


\section{ALTERNATIVE PROCESSING}

\section{MINDS}

\section{Liquid Phase Process:}

$\rightarrow$ Hybrid Process_CVI+EPI + PIP

Objective : Increase thermal conductivity of $\mathrm{SiC}_{f} / \mathrm{SiC}$

by lowering porosity

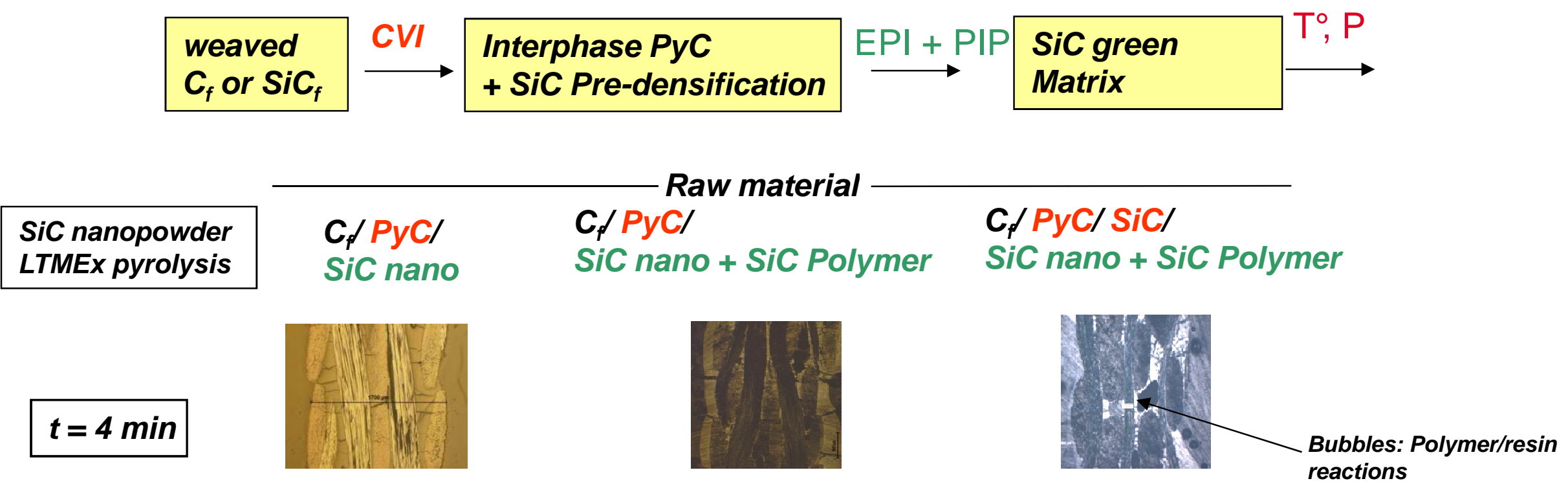

\section{$\rightarrow$ Processing of a SiC layer on composites}

Objectives : Densification and smoothing of $\mathrm{SiC}_{f} / \mathrm{SiC}$ composites 


\section{CQA PROCESSING : «SANDWICH » CONCEPT}

\section{MINDS}

Sandwich concept (CEA Patent)

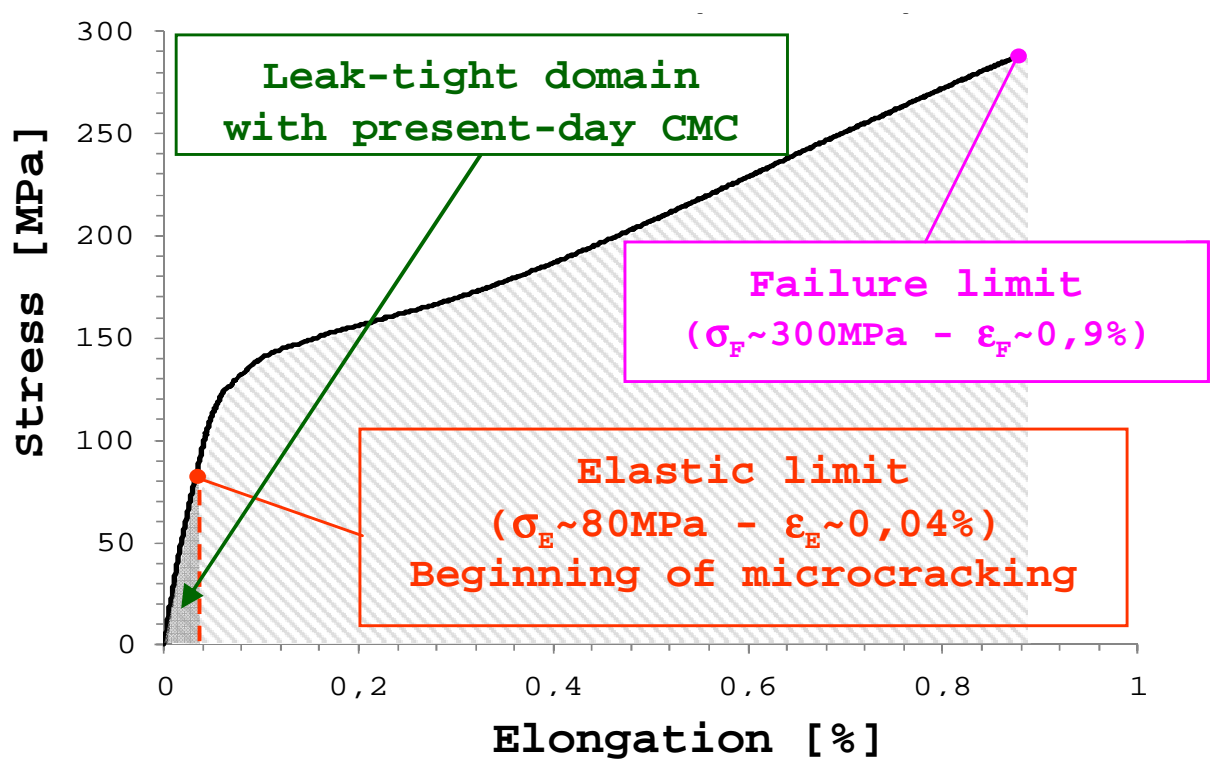

$\square$ - Metallic liner only ensures tightness (processing in LTMEX)

- Composite ensures mechanical resistance

- Process is simple and reproducible

\section{All stages of process are done in CEA}

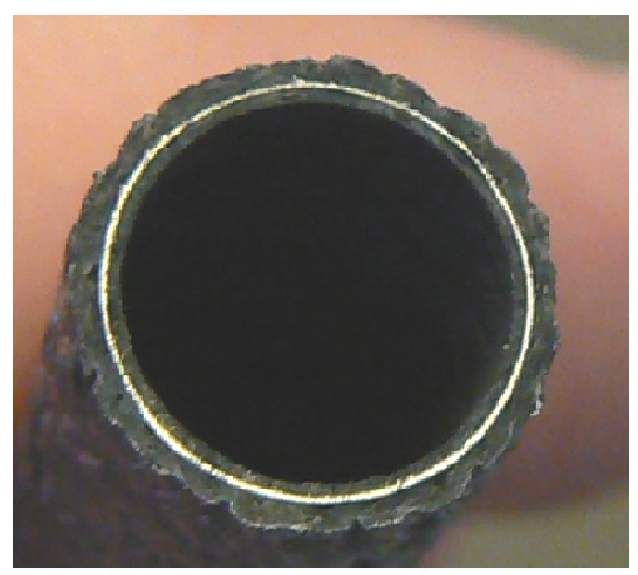

Internal tube SiC/SiC: $\quad$ e 0.3mm liner Ta:

External tube SiC/SiC: $\quad$ e 0.6mm

This type of cladding is supposed to be tight up to failure of the pin 


\section{CQZ « SANDWICH » CONCEPT: WHICH LINER?}

MIN口S

\section{Sandwich Concept - Choice of liner}

$1 / \mathrm{T}(\mathrm{K}-1)$

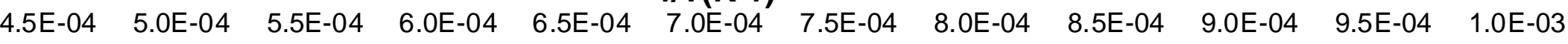

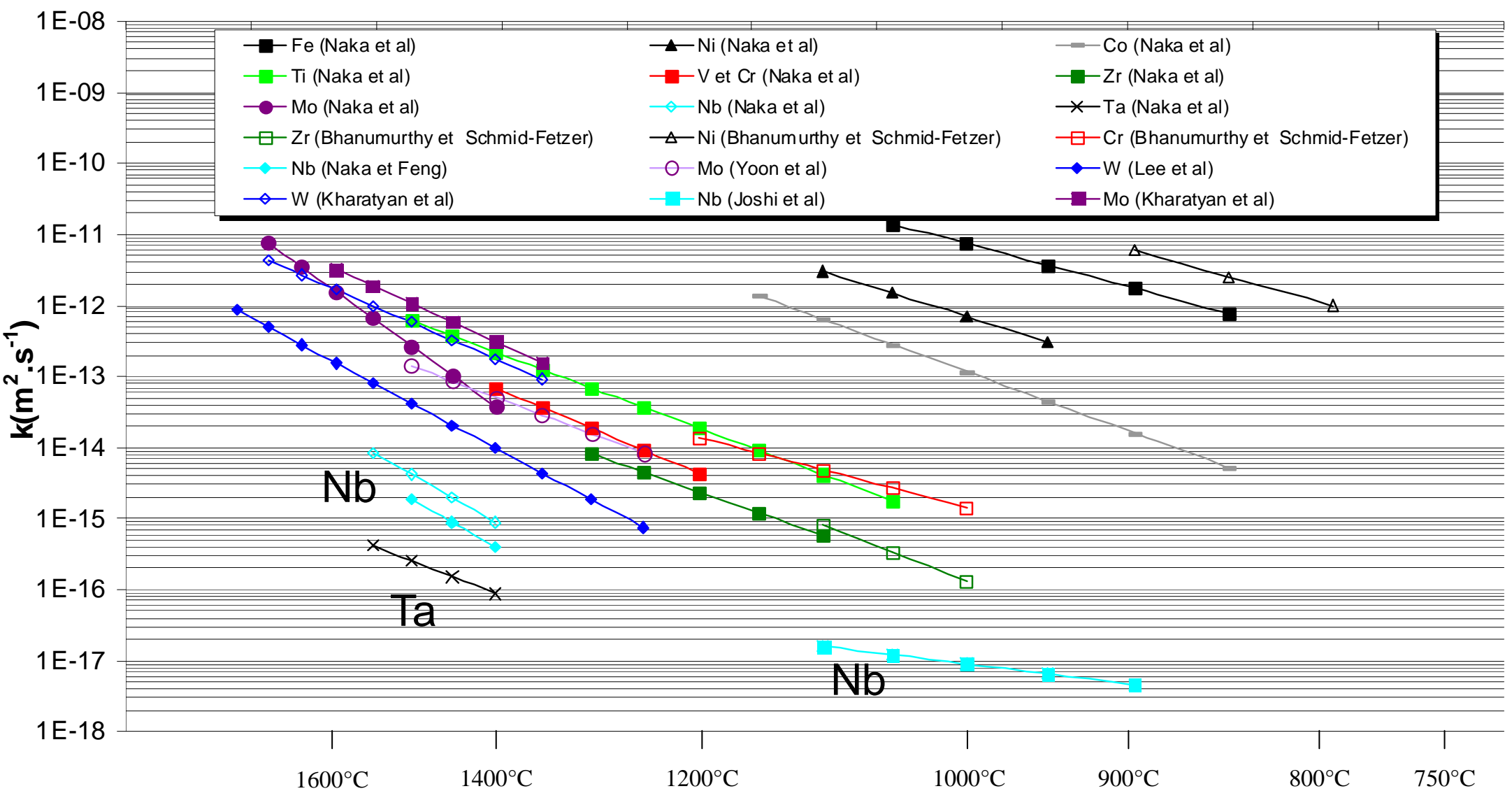

Tantalum and Niobium are the best candidates for GFR Is it still true for PWR or BWR ? 


\section{Cla SANDWICH CHARACTERIZATION: PERMEATION}

\section{$\because$ MINDS}

\section{Sandwich Concept - tightness during tensile test}
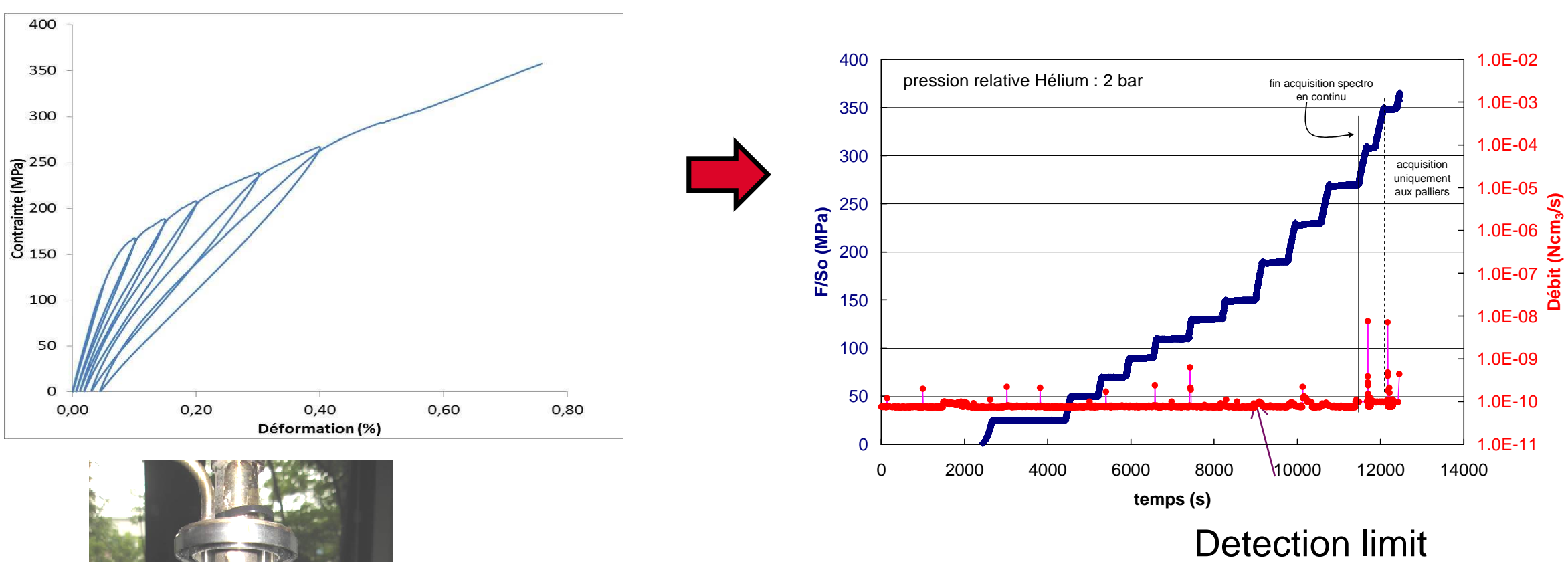

" sandwich » concept allows to keep tightness up to failure of $\mathrm{SiC} / \mathrm{SiC}$ pin cladding

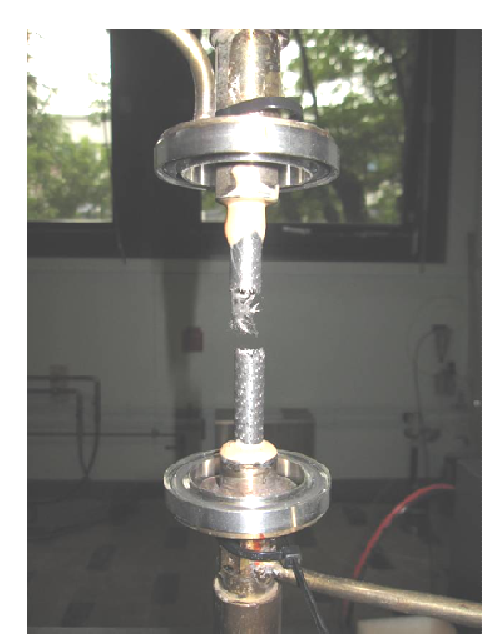

Detection limit 


\section{Cea 3. SANDWICH CHARACTERIZATION}

\section{$\because$ MINDS}

\section{Sandwich Nb - 1000h $-1200^{\circ} \mathrm{C}-$ Sandwich Ta}
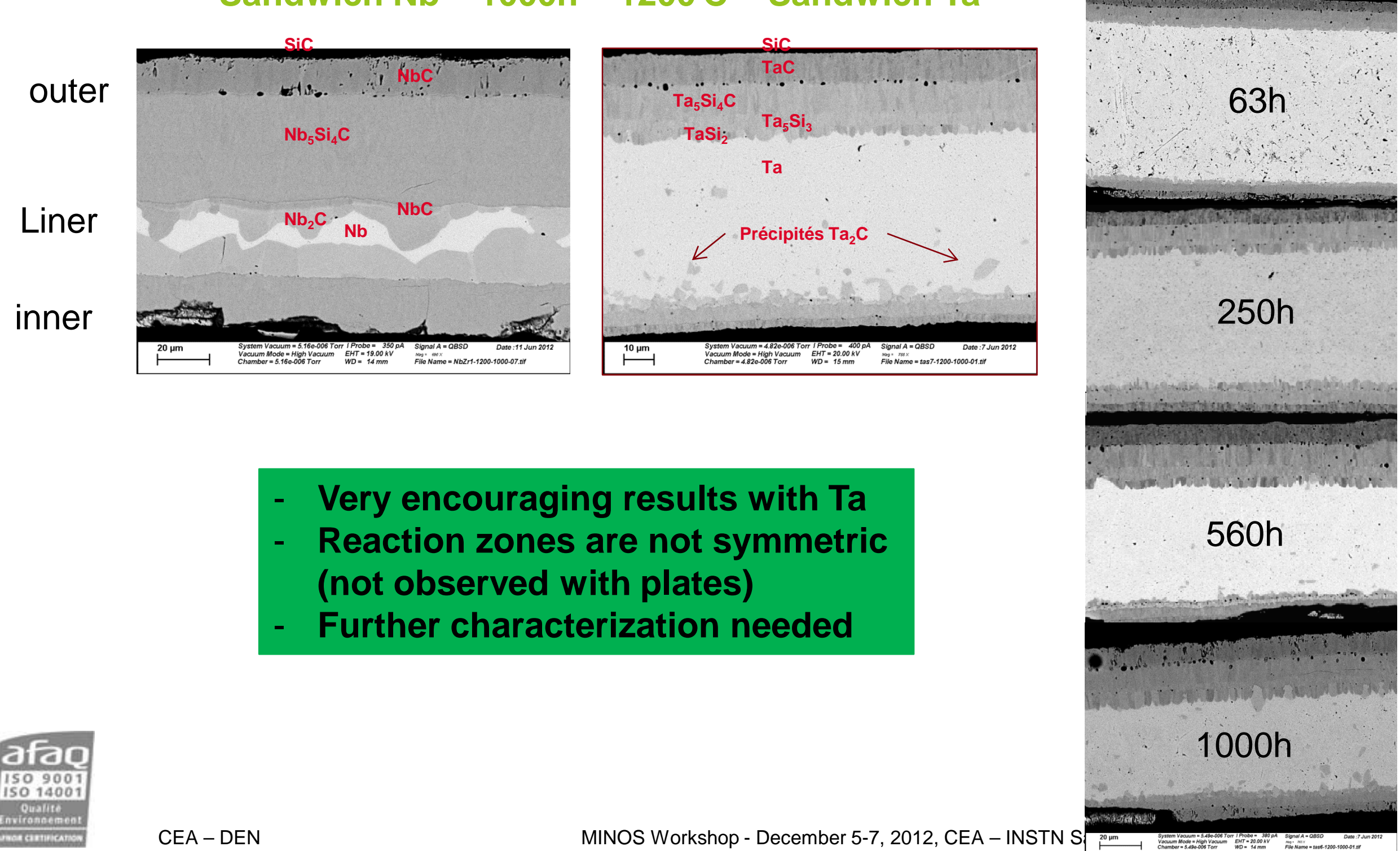

- Very encouraging results with Ta

- Reaction zones are not symmetric (not observed with plates)

- Further characterization needed 


\section{CQA 2. CHARACTERIZATION: IRRADIATION}

\section{MINDS}

Very encourageing results have being obtained with CVI minicomposite (CROCUS irradiation performed in OSIRIS)
NEXT STEP:

$\Rightarrow$ Irradiation in BOR60 (sodium, $550^{\circ} \mathrm{C}$ up to $105-120$ dpa SiC)

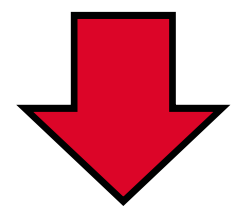

First irradiation of $\mathrm{SiC} / \mathrm{SiC}$ composites at such doses (Including sandwich specimens)

Irradiation should start on december 19, 2012

$\rightarrow$ PIE are expected for 2015

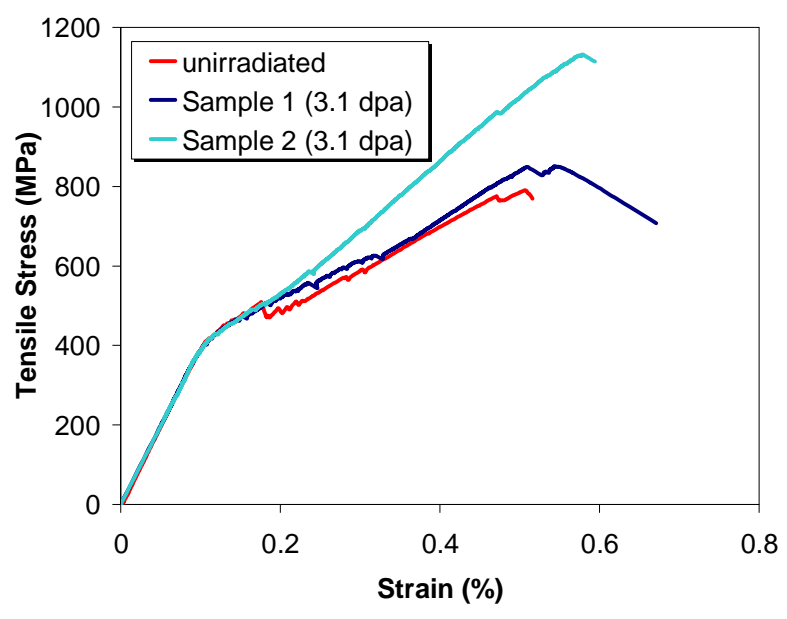

BOR60 - Capsule 3

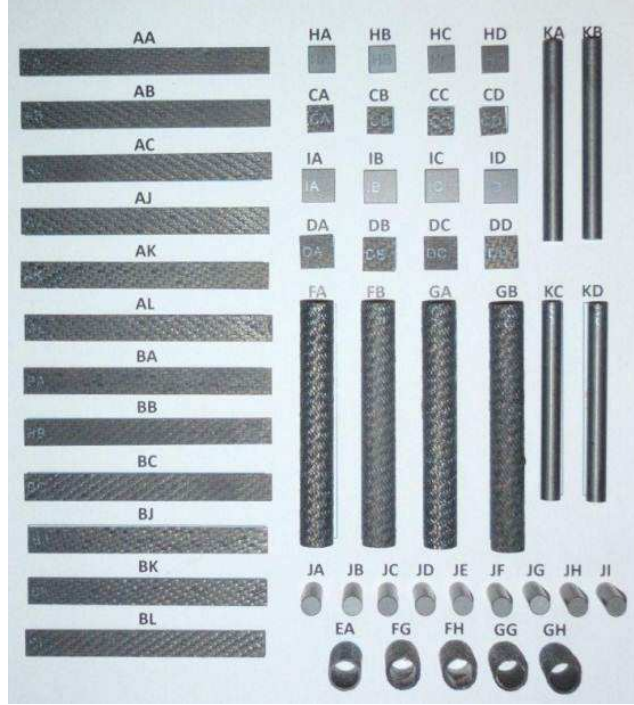




\section{CONCLUSION AND PROSPECTS}

\section{MINDS}

- CMC: Tailoring materials

- Current work focused on fabrication of gastight closed for fast reactor applications (and hexagonal tube)

- Developpment of high skills in CMC manufacturing process at CEA

- Robust program of characterization: assessment of the high quality of the composites made at CEA

- Pursuit of Investment for CMC development: deliveryof a winding machine in the next days and investment of a braiding machine in 2013

- Collaborative work with french universities through Matinex and NEEDs networks (Bordeaux, Mulhouse, Caen, Grenoble) and industrial partners 
Commissariat à l'énergie atomique et aux énergies alternatives

Centre de Saclay | 91191 Gif-sur-Yvette Cedex

T. +33 (0)1690851 66| F. +33 (0)16908 8252

laurent.chaffron@cea.fr

Etablissement public à caractère industriel et commercial | RCS Paris B 775685019
Direction de l'Energie Nucléaire

Département des Matériaux pour le Nucléaire

Service de Recherches Métallurgiques Appliquées Laboratoire de Technologie des Matériaux Extrêmes 